\title{
La epistemología de Toulmin como referente para la selección de contenidos en la enseñanza de la biología
}

\author{
Luz Adriana Rengifo Gallego* \\ Alfonso Claret Zambrano ${ }^{* *}$
}

Artículo recibido: 21-07-2009 y aprobado: 12-11-2009

The epistemology of Toulmin as conceptual framework of reference

for selecting contents for teaching biology

Resumen: Este artículo retoma algunos aspectos relevantes del trabajo de investigación titulado "Elementos epistemológicos de la biología como referentes para su enseñanza" realizado en el marco de la Maestría en Educación de la Universidad del Valle. En este trabajo de investigación, a partir de los planteamientos epistemológicos de Toulmin, se construye una propuesta epistemológica que permite analizar la biología según las posturas de Mayr, Jacob, Piaget y Coleman. Como consecuencia de dicho análisis, se proponen principios que orientan la selección de contenidos de la biología para un curso electivo profesional, en la formación inicial de docentes en el programa de Educación Básica énfasis Ciencias Naturales, de dicha Universidad.

Palabras clave: Epistemología de la biología, análisis epistemológico, enseñanza de la biología, estructura disciplinar de la biología.
Abstract: This article is based on research work entitled: biological epistemological references for teaching biology, this work was realized within of framework of the academic program for master' degree in Universidad of Valle. In this piece of research taking as reference the epistemology of Toulmin an epistemological proposal is presented in order to analyze the biology from different authors, such as: Mayr, Jacob, Piaget and Coleman. Consequently, according to this analysis some principles are designed in order to select the contents of biology for a professional elective course in the initial formation of natural science teachers in such university.

Key words: Epistemology of biology, teaching biology, epistemological analysis, disciplinary structure of the biology.

* Docente Instituto de Educación y Pedagogía. Universidad del Valle luzareng@univalle.edu.co

** Docente Instituto de Educación y Pedagogía. Universidad del Valle zambrano@univalle.edu.co 


\section{Introducción}

Los maestros deben de tomar decisiones para el proceso de enseñanza que van a desarrollar, muchas de ellas de orden curricular, tales como qué conocimiento enseñar y cómo enseñarlo; pero estas decisiones han sido tomadas en algunos casos, en forma acrítica y sin reflexión (Sánchez y Valcárcel, 2000; Escobedo, 1995; Zambrano, 2006) y en ocasiones han resultado siguiendo posturas externas a los docentes que incorporan las propuestas curriculares.

Así por ejemplo, en el caso español sólo cuando se empieza hablar del currículo, después de la década de los 80 , $\mathrm{y}$ adquiere valor la toma de decisiones alrededor de éste, porque antes de esta fecha la programación se había llevado a cabo bajo la presión del control y supervisión de la inspección (Gutiérrez, 2000).

En Colombia existieron programas curriculares únicos de orden nacional hasta 1994, para la enseñanza de la biología, la química y la física, establecidos sin la participación del maestro, con los cuales se esperaba que en todo el país se abarcaran los mismos contenidos de enseñanza en dichas disciplinas (Zambrano, 2006). Actualmente, los maestros cuentan con autonomía para realizar sus propuestas curriculares en dichas disciplinas. ${ }^{1}$ En el ámbito universitario

1 En el marco de la Constitución del 91, en sus artículos $27,69,71$, se ofrece al maestro la libertad en la búsqueda del conocimiento, la enseñanza, el aprendizaje y la investigación; sin embargo los estándares de competencia son un referente curricular a través del cual el Ministerio de Educación Nacional sugiere algunos elementos sobre qué enseñar, aunque no determina la decisión curricular del maestro. los maestros cuentan con la autonomía en la concepción, desarrollo e investigación de sus propuestas curriculares, respaldados por la Constitución de 1991 y la Ley 115 de 1994². Sin embargo las propuestas en este ámbito han sido poco investigadas en el contexto colombiano ${ }^{3}$.

De tal modo, los fundamentos que guían el proceso de enseñanza, ausentes durante mucho tiempo en las prácticas de los maestros del nivel básico y medio por la existencia del currículo único que imponía los fundamentos y en el nivel universitario por la ausencia de investigaciones en esta dirección, ahora cobran importancia por la necesidad en ambos niveles, de que sean construidos por el maestro para analizar el contenido disciplinar y para la toma de decisiones sobre su enseñanza.

Según Valbuena (2007) los fundamentos de estas decisiones recaen sobre 1) El conocimiento didáctico del contenido biológico. 2) El conocimiento académico, compuesto por el conocimiento biológico y científico, el conoci-

2 La Constitución Nacional de Colombia en sus artículos 27,69 y 71; en el artículo 27 plantea que el Estado garantiza las libertades de enseñanza, aprendizaje, investigación y cátedra; en el artículo 69 garantiza la autonomía universitaria y en el artículo 71 establece que la búsqueda del conocimiento y la expresión artística son libres. La Ley 115 en su Capitulo I, artículo 3, establece que el Estado garantiza la autonomía universitaria.

3 De acuerdo con la revisión de Carlos Augusto Hernández del estado del arte de la enseñanza de las ciencias en Colombia de 1989 a 1999, publicada en "La investigación educativa y pedagógica en Colombia. Balance de una época", de COLCIENCIAS en el año 2000, no se alude explícitamente a investigaciones sobre propuestas curriculares en el ámbito universitario. 
miento pedagógico y didáctico general, el conocimiento didáctico de la biología y el conocimiento metadisciplinar. 3) Los conocimientos experienciales y concepciones sobre la biología, la ciencia, la pedagogía, la didáctica general y la didáctica de la biología, siendo éstos de carácter implícito. 4) el conocimiento contextual.

Si bien, se reconoce la intervención de los conocimientos anteriores en la toma de decisiones de un maestro, en este trabajo nos interesa el aspecto epistemológico, por la importancia que éste juega en la comprensión del conocimiento disciplinar a enseñar.

\section{El análisis epistemológico como referente curricular}

Para fundamentar la toma de decisiones curriculares, tales como la selección del contenido a enseñar y el diseño de actividades para la enseñanza, de manera crítica y reflexiva, algunos autores (Adúriz, 2005; Mosquera, 2005; De Pro, 2003; Jiménez, 2003; Zambrano, 2003; Gil, 1993; Mellado y Carracedo, 1993; Colombo y Salinas, 2004) sugieren que los maestros deben tener en cuenta referentes epistemológicos.

Sin embargo, dado que la epistemología de cada una de las diversas disciplinas es diferente porque sus objetos de estudio y preguntas son particulares (Escobedo, 1995), se requiere de análisis epistemológicos específicos de las disciplinas, que permitan conocer cada una de éstas y comprenderlas en su relación y diferencia con las otras, para desde allí fundamentar sus decisiones acerca del diseño de la enseñanza.

Desde la epistemología se identifican los siguientes aspectos: 1) Existe variedad de posiciones conceptuales de "una misma disciplina" así por ejemplo, las miradas que tienen Mayr, Coleman, Jacob y Piaget ${ }^{4}$ sobre la biología, guardan diferencias entre sí. 2) Los maestros se encuentran con variedad de posiciones conceptuales de una misma disciplina cuando buscan tomar decisiones a través de ellas, sobre su enseñanza, aprendizaje y evaluación. 3) Existen variedad de métodos, reglas o criterios para diferenciar, relacionar o analizar la diversidad conceptual frente a las diferentes versiones que existen sobre las disciplinas. Un ejemplo es desarrollado por Canguilhem (1975) quien usa las categorías epistemológicas bachelardianas de obstáculo epistemológico y ruptura epistemológica, para analizar la historia del movimiento reflejo en el siglo XVIII (Bachelard, 1997).

Esto muestra una relación con el conocimiento, su naturaleza, su legitimidad científica, su selección y su organización para su enseñanza; todos estos aspectos representan un interés por el conocimiento científico que debe ser educativamente abordado, lo cual introduce un problema de orden epistemológico en un contexto educativo:

\section{¿Cómo puede un maestro de ciencias tomar decisiones curriculares de selección de contenido, basado en una variedad de posiciones conceptuales sobre la biologia?}

La importancia de la pregunta radica en la necesidad que plantean algunas investigaciones (Adúriz, 2005; Mosquera, 2005; De Pro, 2003; Jiménez, 2003; Zambrano, 2003; Gil, 1993; Mellado y Carracedo, 1993; Colombo y Salinas, 2004) de que el maestro tenga conoci-

4 Se han seleccionado estos autores por tomar un caso particular. 
mientos históricos y epistemológicos que orienten sus decisiones curriculares, conocimientos que son escasos en la formación de maestros.

Investigaciones previas relacionadas con el problema anterior, como las realizadas por García, Pro, y Saura (1995); Jiménez, M. (1996); Díaz, F. (1998); Zambrano, A. (2000); Jiménez, M. (2003) y Zambrano (2005), se han interesado en los aportes que el análisis epistemológico en las disciplinas particulares ofrecen para la enseñanza de las ciencias, principalmente en lo referente a la selección y organización del conocimiento curricular a enseñar.

Estas investigaciones plantean que el análisis epistemológico de una disciplina ayuda a identificar qué se puede enseñar de ella y cómo decidir la organización del conocimiento a enseñar. Sin embargo, hay que reconocer que la epistemología no es el único conocimiento que debe tener en cuenta el maestro en la toma de sus decisiones, ya que, tal como lo plantea Duit (2006), los aportes de la filosofía de la ciencia (epistemología) ${ }^{5}$ por sí solos no son suficientes para la enseñanza de las ciencias, porque se requiere de otras disciplinas como la ciencia misma, la historia de las ciencias, la pedagogía, la psicología, la sociología, la antropología, la lingüística y la ética.

\section{Los criterios epistemológicos}

Plantear una concepción de epistemología exige su ubicación en el campo de la filosofía, por la relación estrecha que, a través del conocimiento, existe entre la

\footnotetext{
5 Aquí se están asumiendo como semejantes.
}

filosofía y la epistemología ${ }^{6}$. Mientras que desde una primera aproximación se puede asumir la epistemología como teoría del conocimiento, la filosofía, en otra primera aproximación, se reconoce por su etimología, según el griego phileo significa amor y sophia, sabiduría, por consiguiente se asume como amor a la sabiduría. Con base en lo anterior, filosofía es el deseo de conocer, en otros términos, desear el conocimiento; en este contexto, le compete a la filosofía conceptualizar al mundo y al hombre, explicar el mundo, la vida y otras preguntas. Es decir, como lo plantea inicialmente Hessen (1998), tener una concepción del mundo y del hombre, o como concluye "es el esfuerzo reflexivo del pensamiento humano por lograr una concepción del universo mediante la ciencia, los valores y la ética".

De acuerdo con Lecourt (1973) la epistemología consiste en identificar y analizar los problemas tal como se plantean y se resuelven en la práctica de los científicos, como un conjunto de relaciones, históricamente determinadas, de producción de conceptos. Según Pérez (1992), Adúriz (2005) y Zambrano (2008), desde la epistemología se plantean preguntas como: ¿qué es una ciencia? ¿En qué consiste el conocimiento científico? ¿Cómo se produce el conocimiento científico? ¿De

6 Pérez (1998) plantea que"hay una tradición inglesa, Philosophy of Sciences, hay una tradición francesa paralela, Epistemologie, y, de acuerdo con las tradiciones intelectuales en que se han formado las universidades latinoamericanas, a veces los académicos se refieren a Epistemología, a veces a Filosofía de la Ciencia". De ahí que en ocasiones se usen estos términos como sinónimos, dejando de lado sus posibles diferencias para otras discusiones. 
qué manera se relaciona el sujeto con el objeto que se conoce? ¿Cómo ocurre la validación del conocimiento científico? ¿En qué contextos se produce y se valida el conocimiento? ¿Cómo se incrementan los conocimientos? ¿Cómo se cambia de un conocimiento a otro? ¿Qué normas y valores guían las ciencias?

Si se realizan estas preguntas desde las perspectivas de Bachelard, Kuhn, Lakatos, Popper, Feyerabend, Matthews, Bordieu, Toulmin u otros, se obtienen respuestas diferentes, porque desde el punto de vista de la interpretación del conocimiento, en cuanto a su desarrollo, su origen, su significado y su historia, $\mathrm{y}$, como consecuencia de lo anterior, su interpretación pedagógica, es variada.

Por otra parte, Toulmin (1977) se refiere al cambio epistemológico de la ciencia para explicar cómo se construyen las disciplinas más o menos separadas y bien definidas, caracterizadas por los intereses académicos de la comunidad, su propio cuerpo de conocimientos y métodos, asemejándolo al proceso de cambio evolutivo gradual de las especies que propone la teoría Darwiniana; este planteamiento se diferencia considerablemente de la explicación de otros autores (Bachelard, 1997; Canguilhem, 1975; Lakatos, 1978; Kuhn, 2004; y otros) sobre el cambio epistemológico de la ciencia.

Toulmin (1977) ofrece, desde su concepción disciplinar, elementos teóricos para desarrollar un análisis epistemológico, afirmando que las características que cambian en una disciplina son los propósitos, conceptos y teorías que resultan de dar respuestas a los problemas disciplinares, además de los procedimientos metodológicos seguidos y las posturas filosóficas predominantes en el pensamiento científico; mientras que los problemas fundamentales son el punto de partida de dichas características.

De allí que para un análisis epistemológico de una disciplina se tengan en cuenta los siguientes criterios teóricos (Rengifo, 2008), conceptualizando los planteamientos de Toulmin (1977) para la comprensión de las disciplinas: 1) Los problemas fundamentales de la disciplina. 2) Sus propósitos. 3) Los conceptos y teorías que resultan de dar respuestas a los problemas. 4) los procedimientos metodológicos seguidos. 5) las posturas filosóficas predominantes en el pensamiento científico.

Dichos criterios permiten analizar epistemológicamente la diversidad conceptual de la biología, vista desde las posturas de algunos autores que abordan el desarrollo de esta disciplina. Así, el papel principal de Toulmin en este trabajo, es ofrecer unos referentes epistemológicos que contribuirán a tomar una postura curricular de la biología, basada en diferentes posturas conceptuales de ella (en este caso las de Mayr, Coleman, Jacob y Piaget).

Este análisis se realiza siguiendo los cinco criterios teóricos previamente proporcionados por Toulmin (1977), en algunos trabajos sobre biología que realizaron los siguientes autores: Mayr, Así es la biología (1998); ; Jacob, La lógica de lo viviente (1970); Coleman, Biología del siglo XIX (2002); y Piaget, Introducción a la epistemología genética. El pensamiento biológico, psicológico y sociológico,

7 Se tuvieron en cuenta algunos aportes complementarios que este autor planteó en su texto ¿Por qué es única la biología? (2006). 
(1979). A través de estas obras se espera analizar la biología como disciplina.

La selección de dichos autores se hizo teniendo en cuenta las siguientes razones: 1) Muestran diferentes posturas epistemológicas de la biología. 2) Abordan la biología en conjunto, mostrando las relaciones conceptuales al interior de ésta. 3) Se muestran en sus tesis, los principales métodos utilizados para el desarrollo de la biología. 4) Los aportes de estos autores se prestan para ser tenidos en cuenta para propuestas educativas, lo cual vale la pena explorar dada la escasez de trabajos de esta naturaleza. 5) Finalmente, porque corresponden a material ampliamente difundido, lo que le permite a un docente acceder a ellos. Hay que reconocer a autores como Giordan (1988), Monod (1993) y Maturana (1990) que si bien abordan aspectos epistemológicos de la biología, no cumplen con la condición de abordarla en conjunto, presentando las relaciones de su estructura conceptual.

\section{La intención educativa del análisis epistemológico}

En el programa Licenciatura en Educación Básica, énfasis en Ciencias Naturales y Educación Ambiental de la Universidad del Valle, los estudiantes reciben los cursos de biología en la Facultad de Ciencias y los cursos pedagógicos y didácticos en el Instituto de Educación y Pedagogía; las electivas profesionales se eligen de ciertos cursos ofrecidos por los dos anteriores o por otras facultades de la universidad. Esta distribución de los cursos ha mostrado una formación centrada en los productos de la biología ${ }^{8}$, que toma los libros de texto como principal referente en la selección del contenido, sin una preocupación por establecer relaciones entre ellos, ni por el abordaje de aspectos metacientíficos. Sin embargo, se considera que los conocimientos en biología que construyan los estudiantes, pueden complementarse en los espacios de las electivas profesionales, con algunos aspectos metacientíficos de esta disciplina.

Reconociendo que el desarrollo de un análisis epistemológico de la biología permite, en primer lugar, conocer su estructura disciplinar (García, Pro, y Saura, 1995; Jiménez, y otros, 2003; Zambrano, 2005) desde diferentes autores de referencia, lo que implicaría analizar, para cada autor, los criterios teóricos propuestos por la concepción disciplinar de Toulmin; y en segundo lugar, que permite establecer un marco intencionalmente educativo de la biología, basado en su diversidad conceptual, que oriente la selección de contenido considerando aspectos metacientíficos; el análisis epistemológico proporcionará al profesor elementos para tomar decisiones curriculares sobre la selección del conocimiento biológico y aspectos metacientíficos a enseñar en una electiva profesional $^{9}$ para el programa ya mencionado, de la Universidad del Valle.

8 Los productos de la biología deben ser de conocimiento de los maestros en formación, pero deben acompañarse de aspectos metacientíficos para su mejor comprensión y del reconocimiento de las características de la actividad científica más acordes con el trabajo de los científicos.

9 Actualmente existe una electiva profesional denominada Educación en Biología donde podrían considerarse estos elementos. 


\section{Estructura disciplinar de la biología}

A continuación se analizarán los criterios disciplinares de Toulmin en las propuestas de los autores de referencia, reconociendo que las preguntas que han estado asociadas a los problemas fundamentales de la disciplina permanecen más o menos constantes a lo largo de la historia y que las posturas filosóficas desde donde se intenta dar respuestas a éstas, las explicaciones que se dan y las metodologías utilizadas para encontrar y validar esas explicaciones, son las que varían en el tiempo (Toulmin, 1977). Esa variación de las explicaciones y de posturas filosóficas hace que a lo largo del tiempo un concepto tenga diferentes conceptualizaciones, lo cual en este trabajo se reconoce pero no se detallará.

De acuerdo con lo que plantea Mayr (1998) se puede considerar que hay cuatro problemas fundamentales alrededor de la biología:

- Describir los organismos vivos, enmarcada en la pregunta del "¿qué?"

- Plantear causas próximas, enmarcada en la pregunta del "¿cómo?"

- Proponer causas remotas, enmarcada en la pregunta del "¿por qué?"

- Plantear múltiples causas, que recoge de todas las preguntas anteriores.

El primero de éstos constituye un momento inicial de cualquier subdisciplina biológica, Mayr lo ejemplifica desde el estudio de la biodiversidad, donde se cuestiona ¿Qué clasificación puede dársele a los organismos existentes y a los extintos? Esto con el propósito de describir la diversidad orgánica, para lo cual los conceptos de taxonomía, sistemática y especie emergen. La metodología para abordar esta problemática es la observación, descripción, clasificación y comparación de los organismos. Lo anterior conceptualizado inicialmente desde una mirada filosófica del mundo como algo estático, que funcionaba como una máquina bien programada por la bondad del Creador y posteriormente, desde una mirada del mundo como algo cambiante.

En el segundo de los problemas es explicar la formación de un nuevo individuo, en él se plantean los siguientes cuestionamientos: ¿Cómo se desarrolla un nuevo individuo a partir de un huevo fecundado? ¿Cuál es la contribución de cada gen al desarrollo del individuo? Estas preguntas tienen como propósito explicar el funcionamiento de un organismo y de sus partes, así como su desarrollo; para esto se requieren de conceptos como fisiología, genética, embriología, reproducción y bioquímica, y de teorías como la celular, de la herencia, la del desarrollo y la de recapitulación. La metodología que se usa para resolver esta problemática se basa en "el método experimental"10, que incluye la comparación de estructuras y funciones de órganos reproductores y modos de cópula, además de la comparación de los procesos de desarrollo entre los distintos organismos. La postura filosófica alrededor de esta problemática se encuentra marcada por la oposición entre dos tendencias: la tendencia fisicista de mirar el individuo por sus partes considerándolo como similar a una máquina, y la tendencia vitalista.

En el tercer problema se encuentra el estudio de la evolución; a su alrededor se plantean inquietudes como ¿Por qué

\footnotetext{
10 El método experimental era entendido como aquél propio de la física, particularmente de la determinista.
} 
existen ciertos organismos en zonas específicas del mundo? ¿Por qué ciertas características y comportamientos de los organismos? y ¿Pueden evolucionar los organismos dando origen a variedad de especies? Los propósitos son intentar explicar los motivos por los que un organismo es como es, entendiéndolo como producto de la evolución; en este sentido son centrales los conceptos de evolución adaptación y especiación y las teorías de evolución (gradualismo, saltacionismo), ascendencia común y de la selección natural.

La metodología para abordar esta problemática es la observación, comparación y realización de inferencias derivadas de las observaciones realizadas a partir de narraciones históricas ${ }^{11}$, apoyadas en gran parte en el registro fósil. Lo anterior se enmarca en una postura filosófica de un mundo constante (aportado por la visión fijista) que se contrasta con un mundo cambiante, una mirada del individuo en contraste con la mirada en la población, y una mirada organicista que reconoce la idea del reduccionismo de poder explicar los fenómenos a partir de reducirlos a sus componentes más pequeños, no funciona para explicar las características de los organismos que se manifiestan en los niveles de organización superiores (tales como la competencia, el cortejo, entre otras).

El cuarto problema planteado por Mayr (1998) parte del estudio de la ecología bajo los siguientes cuestiona-

11 La narración histórica es reconocida por Mayr como una metodología científica introducida por Darwin, que consiste en la determinación de causas últimas por inferencias. mientos: ¿Cuáles son las interacciones entre los organismos y su ambiente y en qué consisten éstas? ¿Qué propiedades fisiológicas, de conducta y morfológicas, permiten a una especie sobrevivir en su ambiente? Los propósitos alrededor de esta problemática se centran en el interés por la densidad de las poblaciones, la estructura de las comunidades, el conocimiento de la cantidad de materia y energía que circula a través de los ecosistemas y el conocimiento de las adaptaciones de conducta y modo de vida de los organismos. Desde allí son centrales los conceptos de población, adaptación, nicho, competencia, estrategias reproductivas, densidad de las poblaciones, depredadores, presas, co-evolución, cadena alimentaria. Las metodologías utilizadas alrededor de esta problemática son la comparación, el experimento (de control de variables), las conjeturas, la comprobación de teorías explicativas. Las posturas filosóficas desde las que se piensa lo anterior son el fisicismo y el evolucionismo.

Es importante mencionar que según lo muestra la historia, se han intentado explicar los fenómenos biológicos mencionados, desde una sola causación, pero para Mayr el hacerlo desde las causas próximas y remotas corresponde a una mirada más completa.

Coleman (2002) $)^{12}$ propone tres problemas fundamentales alrededor de la biología:

12 A pesar de que Coleman titula su texto como $\mathrm{La}$ biología en el siglo XIX, no incluye allí dos ámbitos de esta ciencia que se desarrollaron en tal siglo: la herencia mendeliana y la propuesta de la microbiología desde los trabajos de Pasteur. 
- Las formas de los organismos. Implica explorar su composición orgánica.

- Las funciones de éstos. Se concentra en estudiar los procesos vitales de los organismos.

- Sus relaciones entre sí y con el ambiente cambiante, tanto en el mundo presente como en el del pasado.

En el primero de éstos se encuentran los siguientes interrogantes: ¿Qué es un organismo vivo? ¿Cómo está constituido el organismo vivo? ¿Cómo se originan? El propósito de las preguntas se centra en conocer las unidades que estructuran la vida y el modelo de distribución dentro de los organismos. En cuanto a los conceptos que permiten alcanzar estos propósitos y resolver estos interrogantes, se tienen los tejidos y la célula, en cuanto a las teorías están la celular, del desarrollo y de la recapitulación. Las metodologías utilizadas son el análisis de las estructuras de los organismos en relación con sus finalidades, las observaciones microscópicas, la fijación, corte y tinción de células, el examen y comparación del desarrollo en una amplia gama de organismos. Inicialmente estos aspectos estuvieron marcados por una idea estática del mundo vivo, predominó una visión esencialmente estructural del organismo vivo, y se buscó explicar la formación celular desde la cristalización inorgánica para quitarle el carácter metafísico dado por los vitalistas.

En el segundo problema se plantean estos interrogantes: ¿Cómo explicar los complejos procesos fisiológicos de los seres vivos? ¿Cuál es el lugar del organismo donde ocurren cada uno de esos procesos? El propósito de estas preguntas es conocer los procesos de desarrollo y funcionamiento por los cuales se forman las unidades estructurantes de la vida y los organismos. De ahí que los conceptos centrales relacionados con esta problemática sean la célula y la fisiología, y en esta última, la respiración, digestión, circulación y excreción. Las metodologías usadas son el análisis de los órganos y sistemas, y posteriormente, de los procesos celulares, utilizando prácticas experimentales derivadas de la física y la química así como la comparación del organismo vivo con las máquinas y la vivisección. Dentro de las posturas filosóficas se manifiestan las miradas idealistas del organismo vivo que se contraponen a las nociones mecanicistas-materialistas del mismo, que lo comparan con las máquinas.

El tercer problema se encuentra asociado a interrogantes como éstos: ¿Cómo se originan las especies? ¿Qué causas podrían asignarse a las diferencias entre especies? ¿Podía transformarse una especie, a través del tiempo, en otra relacionada pero esencialmente distinta? Los propósitos a los que responden éstas son explicar los cambios en la forma y el comportamiento de los organismos a través del tiempo, y en conocer estructura y cambio de la superficie de la Tierra. Así, los principales conceptos asociados a este problema son la adaptación, la recapitulación, la transmutación o evolución de la naturaleza orgánica, la selección natural y el saltacionismo.

Las metodologías utilizadas para responder dichos interrogantes fueron la descripción, interpretación y sistematización de los fósiles, el uso de éstos para realizar sucesiones históricas, la comparación de especies similares en zonas geográficas distintas, la comparación de especies actuales con las 
extintas, la cría experimental de organismos, la aplicación de la estadística para estudiar variaciones en grandes poblaciones. Como postura filosófica se plantea un cambio de la concepción estática de la naturaleza, a una concepción dinámica marcada por la idea del tiempo, y se empieza a prestar atención al estudio de las poblaciones en vez de mirar al individuo.

En lo que a Jacob (1970) se refiere, el problema central de estudio es la herencia, que se plantea problemáticas diferentes dependiendo del nivel que se estudie y según el momento histórico y conceptual en el cual fue abordado, que puede ser:

- Desde las estructuras visibles. Se inscribe en una perspectiva naturalista, s. XVII hasta mediados s. XIX.

- De la organización. Se enmarca en el "nacimiento de la biología como ciencia" en donde la postura vitalista jugó un papel preponderante; segunda mitad del s. XIX.

- Del tiempo. Corresponde al reconocimiento de un mundo cambiante que permite la concepción de evolución; mediados del s. XIX.

- De los cromosomas y genes. Se inscribe en la necesidad de estudiar el organismo hacia su interior; segunda mitad s. XIX y principios del XX.

- De las moléculas (corresponde a estudiar el interior de la célula; mediados del s. XX.

En el primer apartado se plantean los interrogantes: ¿Cómo se forma un ser? ¿Por qué el niño se parece a sus padres? ¿Cuáles son las leyes del movimiento en el cuerpo de los animales? ¿Cuál es la similitud entre los seres, cuáles son sus relaciones, sus identidades y sus diferencias? ¿Cómo clasificar los seres vivos? El propósito principal de a éstos es conocer la estructura visible de los seres vivos y su clasificación. Los conceptos principales que resultan son reproducción, fisiología, y especie.

En la metodología para responder estos interrogantes se encuentra, para el estudio de la fisiología, el estudio desde las leyes del movimiento y el planteamiento de analogías entre el funcionamiento de los órganos del cuerpo y algunas cosas del mundo; en la historia natural, se realiza observación objetiva de los seres vivos, su descripción; también, en algún momento, el intento de cruces de organismos de diferentes especies y la realización de árboles genealógicos, apoyados en el cálculo de probabilidades.

En lo anterior se manifiesta una oposición entre las corrientes mecanicista y vitalista. Sin embargo, Jacob introduce que esta forma de abordar el organismo vivo a partir de las estructuras visibles, corresponde a una tendencia integrista, para los biólogos que lo abordan, "el órgano y la función no tienen más interés que en el seno de un todo constituido, y no sólo por el organismo, sino por la especie con todo su cortejo de sexualidad, de presa, de enemigos, de comunicación, de ritos”. El biólogo integrista se niega a considerar que todas las propiedades de un ser vivo, su comportamiento, sus logros puedan explicarse sólo por sus estructuras moleculares. Para él, la biología no puede reducirse a la física y a la química. No se trata de que quiera invocar lo incognoscible de una fuerza vital sino de que, en cualquier nivel, la integración otorga a los sistemas propiedades que no tienen sus elementos" (Jacob, 1970). 
En el segundo apartado se proponen los interrogantes: ¿Cómo se forma un ser vivo? (también se plantea desde el nivel anterior) ¿Cuál es la composición elemental de un organismo vivo? ¿Dónde se sitúan las propiedades vitales del ser vivo? Los propósitos que se plantean son, relacionar la superficie del ser y la profundidad, el órgano y la función, lo visible y lo invisible, así como el conocimiento de todas las facultades que son propias a cada uno de los seres orgánicos (la vida).

Así, los conceptos centrales que responden a esos interrogantes son la fisiología (integrada) asociada al órgano y la función, adaptación, sustancias orgánicas (azúcares, grasas, proteína), anatomía comparada, tejidos, reproducción, célula, y la teoría celular. Las metodologías utilizadas son la comparación del órgano en diferentes animales, o los distintos tipos de órganos en el mismo animal, el uso de la metodología de la química orgánica para reconocer las sustancias de la materia viva; también el uso de lentes que aumentan la resolución del microscopio, la tinción de células y la disociación de tejidos a través del uso de sustancias y calor. Finalmente predomina, como postura filosófica, la concepción de las unidades de un organismo como un conjunto integrado de funciones en la totalidad de este.

Los interrogantes para el tercer nivel son: ¿Varían los organismos vivos? ¿Cuál es la mecánica de variación de los organismos vivos? Los propósitos de éstos son unir entre sí, y a través del tiempo, a todos los seres vivos en una historia común, viéndose como derivados unos de otros, y conocer las condiciones ambientales en las que se encuentran los organismos relacionándolas con la organización de éstos. Los conceptos centrales que resultan de esto son reproducción, herencia, adaptación, teoría evolutiva, especie, competencia, selección artificial y selección natural.

Las metodologías utilizadas son la reconstrucción de la estructura general de los fósiles de los organismos y el estudio de las capas geológicas en las que éstos fueron encontrados para la descripción del hábitat en el que vivieron, el conocimiento de la distribución de los organismos actuales en todo el globo, el análisis de las variaciones de las poblaciones y no de los individuos y el uso de mecanismos utilizados por los criadores, para explicar la variación de las especies que ocurre espontáneamente en la naturaleza. La base filosófica de lo anterior es una postura integrista o evolucionista de la biología, así como una concepción de los seres vivos como mutables, en oposición a una mirada fijista.

En el cuarto nivel se plantea: ¿Cuál es la función de cada uno de los órganos de los organismos vivos? ¿Cuántas son las diferentes formas bajo las cuales aparecen los descendientes de los híbridos y cuáles son sus relaciones estadísticas? ¿Qué papel desempeña el núcleo y el citoplasma en el funcionamiento de la célula? ¿Qué papel desempeñan los cromosomas de la célula? ¿Qué sustancias poseen los cromosomas que le dan la capacidad de reproducirse? De ahí que el propósito de estas preguntas sea analizar los constituyentes de los seres vivos y sus transformaciones en relación con el funcionamiento del organismo; de esto se manifiestan conceptos como reproducción, fisiología (respiración, 
digestión, transpiración, hormonas, nervios, cerebro, etc.), homeostasis, cromosomas (célula), genes, mutación, enzimas.

Dentro de las metodologías utilizadas para este caso, se encuentran: el análisis de los fenómenos que se producen en el organismo por medio de los métodos de la física y de la química, con los trabajos realizados por Claude Bernard; la comparación del funcionamiento normal de las estructuras del organismo con su patología, sea natural o provocada por medios mecánicos (extirpación) o por sustancias químicas tóxicas (inyección de parafina), se usa el microscopio y la tintura de las estructuras celulares para su observación, así como los métodos físicos como la ultracentrifugación, para extraer los contenidos celulares; también se experimentos que favorecían las mutaciones y permitían conocer sus frecuencias; para el estudio de la reproducción y la herencia se da la observación no de individuos sino de poblaciones unidas por lazos de parentesco y se realizan experimentos con híbridos, entre los que se encuentran los trabajos realizados por Mendel.

Como concepción filosófica sobresale la postura "tomista o reduccionista"13 de la biología, la cual ofrece una mirada cartesiana de la complejidad del organismo vivo; desde la tendencia reduccionista "el organismo es sin duda un todo, pero que se debe explicar sólo por las propiedades de sus partes... sensible a la unidad de composición y de funcionamiento que observa detrás de la diversidad de los seres vivos, en los logros del organismo ve la expresión

13 Expresión asignada por Jacob. de sus reacciones químicas... se trata de aislar los constituyentes de un ser vivo y de encontrar las condiciones que le permitan estudiarlo en un tubo de ensayo. Su esperanza consiste en descomponer la realidad hasta el mayor grado posible para analizar los elementos con el ideal de pureza y de certeza que representan las experiencias de la física y de la química..." (Jacob, 1970).

Para el quinto nivel se encuentran preguntas como ¿Qué determina la forma de los seres vivos, sus propiedades y funcionamiento? ¿Cuál es la dinámica de las transformaciones de los seres vivos? Los propósitos fueron estudiar el problema de la reproducción a este nivel, conocer la composición de las moléculas, su organización interna y los procesos de su síntesis. Los conceptos relevantes que resultan son la reproducción, herencia, adaptación, moléculas (acido desoxirribonucleico), mutaciones, recombinaciones. Las metodologías utilizadas para este caso son principalmente, el uso de la "cromatografía", radioisótopos y microscopio electrónico, que permiten hacer la distinción entre compuestos muy parecidos, y el uso de microorganismos en especial las bacterias y los virus, para la extracción de material genético. Predomina una postura tomista o reduccionista de la biología.

Finalmente, el estudio de la biología, para Piaget (1979), se centra en dos problemáticas:

- La sistematización y comparación de los organismos

- El planteamiento de causas

Desde el primero de éstos propone como interrogantes ¿Cómo clasificar los organismos vivos? ¿Cuáles son los grados de semejanza y diferencia entre las 
especies? Los propósitos que se plantean son sistematizar los organismos vivos y comparar los organismos vivos entre sí y con sus estructuras. Los conceptos que se sugieren para dar respuestas a estas preguntas son especie, anatomía comparada, genotipo y fenotipo y las teorías de la herencia y variación. La metodología es la clasificación de los organismos, basándose en relaciones de parentesco probadas con la observación y en otros casos con comparaciones anatómicas.

La postura filosófica que se manifiesta es una idea inicial de las especies invariables y permanentes, que luego se transformaron en variables y susceptibles de transformarse unas en otras, así como en una idea basada en procesos históricos o diacrónicos que presentan una cierta irreversibilidad ligada al transcurso de los acontecimientos en el tiempo; asociado a esto se manifiesta el pensamiento basado en un modelo de razonamiento por puros agrupamientos lógicos, es decir por cuantificación exclusivamente intensiva, y que no se basa en "grupos matemáticos, es decir extensivos o métricos".

Las preguntas, desde el segundo de los problemas, son: ¿Cómo ocurren las actividades del organismo? ¿De dónde provienen los organismos? ¿Cómo se desarrollan los individuos? El propósito de éstas es proponer causas a los procesos de los organismos vivos. De ahí que sean importantes los conceptos de fisiología (circulación, intercambio gaseoso, trabajo muscular, calor animal, equilibrio alimentario y energético), embriología y desarrollo del individuo, totalidad, finalidad, transmutación y la ley biogenética (correspondencia entre los niveles de la ontogénesis y de la filogénesis).
La metodología utilizada es adecuar los métodos físico-químicos a los mecanismos observados in vivo tanto como in vitro. Esto basándose en el pensamiento filosófico que parte de la consideración de la forma total del organismo, interpretada desde el logicismo y sustancialismo animista, que luego el conocimiento fisiológico lleva a recurrir a lo cuantitativo, dado el análisis físico y químico de los funcionamientos particulares del organismo. La propuesta también es dominada por los conflictos entre el vitalismo y el mecanicismo, pero marcada por el pensamiento de las interacciones causales de carácter sincrónico, que pueden ser reducidas con mayor facilidad a la medición físicoquímica.

\section{Estructura educativa de la biología}

De lo anterior se logra percibir que, entre las miradas que los autores analizados tienen sobre la estructura disciplinar de la biología, existen algunas diferencias, dadas posiblemente por los énfasis de formación de éstos (evolucionista, historiador, médico, biólogo del desarrollo, respectivamente); sin embargo, se intentará reconocer algunos aspectos comunes en las posturas de éstos; en otros casos estas posturas complementarán una estructura de la biología que se piense para la enseñanza de algunos aspectos metacientíficos de dicha disciplina en un curso electivo profesional, para maestros de ciencias naturales en formación inicial. La información que se presenta en la tabla 1 aparece el reconocimiento de aspectos comunes y complementarios de los planteamientos de los autores.

Reconociendo que los elementos analizados para cada uno de los autores 
se encuentran relacionados entre sí y desde ejes diferentes para cada uno de éstos, se presenta en la figura 1., una forma de relacionar los conceptos y problemas existentes en los procesos de construcción de conocimiento biológico, pensando en los contenidos a enseñarse en un curso electivo profesional para maestros en formación inicial, donde se busque formar una mirada general de la biología, donde se aprenda de ella y sobre ella ${ }^{14}$ simultáneamente, que tenga en cuenta la naturaleza epistemológica de la biología.

En la figura 1 se muestra que puede presentarse la biología como el estudio de la vida en dos niveles: 1) La diversidad de organismos vivos. 2) Los organismos vivos en sí, lo que implica, según Jacob, realizar una mirada integrista (o evolucionista) desde el primero, mientras que el segundo requiere de una mirada tomista (o reduccionista) ${ }^{15}$.

Desde el nivel de la diversidad biológica, interpretado principalmente desde Mayr y Coleman, se busca: A) Describir las diversas formas de vida. B) Explicar cómo se forma esa diversidad de formas vivientes. C) Explicar las complejas interacciones de estas formas vivientes entre sí y con su ambiente cambiante (ver figura 1).

14 Retomando los planteamientos de Duschl (1997).

15 En el sentido que le da Jacob (1970).

\begin{tabular}{|c|c|c|c|c|c|}
\hline & $\begin{array}{l}\text { Problemas } \\
\text { generales }\end{array}$ & Propósitos & $\begin{array}{l}\text { Conceptos } \\
\text { y teorías } \\
\text { generales }\end{array}$ & $\begin{array}{l}\text { Procedimientos } \\
\text { metodológicos }\end{array}$ & Postura filosófica \\
\hline \multirow{4}{*}{ 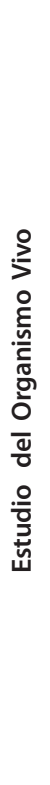 } & $\begin{array}{c}\text { ¿Qué } \\
\text { clasificación } \\
\text { se puede dar a } \\
\text { los organismos } \\
\text { vivos? }\end{array}$ & $\begin{array}{l}\text { Describir y } \\
\text { sistematizar la } \\
\text { diversidad de } \\
\text { organismos vivos }\end{array}$ & Taxonomía & $\begin{array}{l}\text { Observación, } \\
\text { descripción y } \\
\text { comparación } \\
\text { de los } \\
\text { organismos }\end{array}$ & $\begin{array}{l}\text { Inicialmente un } \\
\text { mundo estático; } \\
\text { posteriormente } \\
\text { cambiante }\end{array}$ \\
\hline & $\begin{array}{c}\text { ¿Cómo está } \\
\text { constituido el } \\
\text { organismo vivo? }\end{array}$ & $\begin{array}{c}\text { Conocer las } \\
\text { unidades } \\
\text { estructurantes de } \\
\text { los organismos } \\
\text { vivos }\end{array}$ & Teoría celular & $\begin{array}{c}\text { Uso del } \\
\text { microscopio } \\
\text { y técnicas } \\
\text { asociadas a su } \\
\text { manejo }\end{array}$ & $\begin{array}{l}\text { Inicialmente marcadas } \\
\text { por el vitalismo; } \\
\text { posteriormente una } \\
\text { visión estructural } \\
\text { integrista }\end{array}$ \\
\hline & $\begin{array}{l}\text { ¿Cómo se forma } \\
\text { y desarrolla un } \\
\text { organismo vivo? }\end{array}$ & $\begin{array}{l}\text { Explicar el } \\
\text { proceso de } \\
\text { formación y } \\
\text { desarrollo de los } \\
\text { organismos vivos }\end{array}$ & $\begin{array}{l}\text { Reproducción } \\
\text { y desarrollo. } \\
\text { Microbiología.* }\end{array}$ & $\begin{array}{l}\text { Observación } \\
\text { y seguimiento } \\
\text { del desarrollo } \\
\text { de los } \\
\text { organismos }\end{array}$ & $\begin{array}{c}\text { Entre las tendencia } \\
\text { mecanicista - fisicista } \\
\text { y el vitalismo }\end{array}$ \\
\hline & $\begin{array}{l}\text { ¿Por qué un } \\
\text { organismo vivo } \\
\text { se parece con } \\
\text { sus padres? }\end{array}$ & $\begin{array}{c}\text { Predecir las } \\
\text { posibles } \\
\text { características } \\
\text { de los organismo } \\
\text { vivos }\end{array}$ & Herencia & $\begin{array}{l}\text { Estudio de } \\
\text { poblaciones } \\
\text { y manejo de } \\
\text { probabilidades } \\
\text { estadísticas }\end{array}$ & $\begin{array}{l}\text { Entre la oposición } \\
\text { del mecanicismo } \\
\text { y el vitalismo; } \\
\text { posteriormente una } \\
\text { postura integrista }\end{array}$ \\
\hline
\end{tabular}

* Ninguno de los cuatro autores abordados en el análisis da suficiente relevancia al concepto de microbiología, sin embargo, Giordan et al (1988) y Serres (1991) permiten reconocerlo asociado al cuestionamiento de cómo se forma un organismo vivo y a todo el debate sobre la generación espontánea. 


\begin{tabular}{|c|c|c|c|c|c|}
\hline \multirow{5}{*}{ 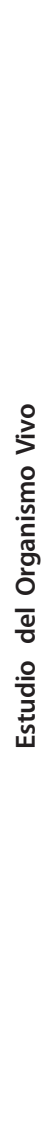 } & $\begin{array}{l}\text { ¿Qué determina } \\
\text { la forma de los } \\
\text { seres vivos, sus } \\
\text { propiedades y } \\
\text { funcionamiento? }\end{array}$ & $\begin{array}{l}\text { Conocer la } \\
\text { composición de } \\
\text { los organismos } \\
\text { vivos }\end{array}$ & $\begin{array}{l}\text { Cromosomas. } \\
\text { Genes }\end{array}$ & $\begin{array}{l}\text { Trabajo } \\
\text { "experimental" } \\
\text { en el que se } \\
\text { buscan conocer } \\
\text { las sustancias }\end{array}$ & $\begin{array}{l}\text { Postura tomista } \\
\text { o reduccionista; } \\
\text { mirada cartesiana de } \\
\text { la complejidad del } \\
\text { organismo vivo }\end{array}$ \\
\hline & $\begin{array}{l}\text { ¿Qué determina } \\
\text { la forma de los } \\
\text { seres vivos, sus } \\
\text { propiedades y } \\
\text { funcionamiento? }\end{array}$ & $\begin{array}{l}\text { Conocer la } \\
\text { composición de } \\
\text { los organismos } \\
\text { vivos }\end{array}$ & $\begin{array}{l}\text { Cromosomas. } \\
\text { Genes }\end{array}$ & $\begin{array}{l}\text { Trabajo } \\
\text { "experimental" } \\
\text { en el que se } \\
\text { buscan conocer } \\
\text { las sustancias }\end{array}$ & $\begin{array}{l}\text { Postura tomista } \\
\text { o reduccionista; } \\
\text { mirada cartesiana de } \\
\text { la complejidad del } \\
\text { organismo vivo }\end{array}$ \\
\hline & $\begin{array}{l}\text { ¿Cómo se } \\
\text { originan las } \\
\text { variedades de } \\
\text { organismos? }\end{array}$ & $\begin{array}{l}\text { Explicar el } \\
\text { proceso de } \\
\text { variación de los } \\
\text { organismos para } \\
\text { constitución de } \\
\text { nuevas especies }\end{array}$ & $\begin{array}{l}\text { Teoría } \\
\text { evolutiva }\end{array}$ & $\begin{array}{l}\text { Recolección de } \\
\text { datos históricos } \\
\text { (narrativas } \\
\text { históricas) }\end{array}$ & $\begin{array}{l}\text { Un contraste } \\
\text { entre fijismo y } \\
\text { evolucionismo, entre } \\
\text { la mirada organicista } \\
\text { y la reduccionista, } \\
\text { entre el estudio de } \\
\text { los individuos y las } \\
\text { poblaciones. }\end{array}$ \\
\hline & $\begin{array}{l}\text { ¿En qué consisten } \\
\text { las interacciones } \\
\text { entre los } \\
\text { organismos y su } \\
\text { ambiente? }\end{array}$ & $\begin{array}{l}\text { Conocer las } \\
\text { relaciones de } \\
\text { los organismos } \\
\text { vivos entre sí y } \\
\text { con el ambiente } \\
\text { cambiante }\end{array}$ & Ecología & $\begin{array}{l}\text { Observación, } \\
\text { descripción y } \\
\text { comparación } \\
\text { de los } \\
\text { organismos; } \\
\text { manejo de } \\
\text { algunas } \\
\text { variables }\end{array}$ & $\begin{array}{l}\text { Marcadas por } \\
\text { el fisicismo y el } \\
\text { evolucionismo }\end{array}$ \\
\hline & $\begin{array}{l}\text { ¿Qué determina } \\
\text { la forma de los } \\
\text { seres vivos, sus } \\
\text { propiedades y } \\
\text { funcionamiento? }\end{array}$ & $\begin{array}{l}\text { Conocer la } \\
\text { composición de } \\
\text { los organismos } \\
\text { vivos }\end{array}$ & $\begin{array}{l}\text { Cromosomas. } \\
\text { Genes }\end{array}$ & $\begin{array}{l}\text { Trabajo } \\
\text { "experimental" } \\
\text { en el que se } \\
\text { buscan conocer } \\
\text { las sustancias }\end{array}$ & $\begin{array}{l}\text { Postura tomista } \\
\text { o reduccionista; } \\
\text { mirada cartesiana de } \\
\text { la complejidad del } \\
\text { organismo vivo }\end{array}$ \\
\hline
\end{tabular}

Tabla 1. Conocimiento biológico propuesto para un curso electivo profesional

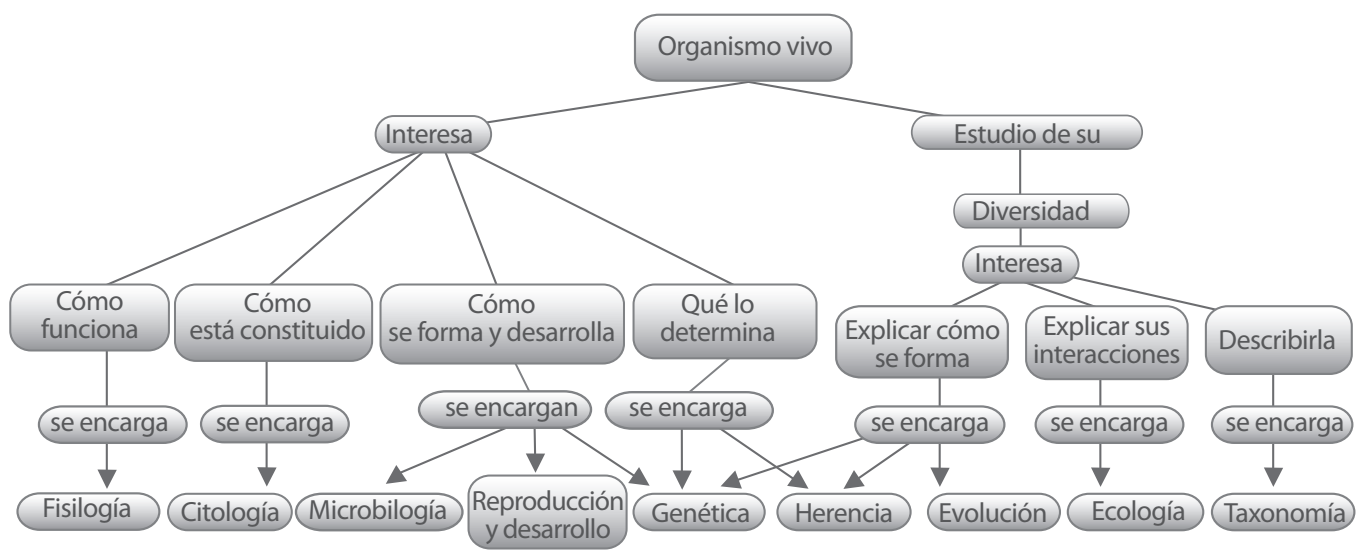

Figura 1. Relación de los problemas existentes en el estudio del organismo vivo. 
Desde el nivel del organismo vivo, interpretando desde Mayr, Coleman, Jacob y Piaget, el interés está en: A) Explicar cómo se forma y desarrolla el individuo. B) Explicar cómo funciona el individuo. C) explicar cómo está constituido. D) identificar qué determina que sea como es (ver figura 1).

Abordar el estudio de estas problemáticas biológicas, independientemente del orden que el maestro quiera establecer, en relación con las posturas filosóficas presentes en el pensamiento de quienes propusieron explicaciones a éstas, los propósitos de abordarlas, los conceptos fundamentales que resultaron y los procedimientos metodológicos realizados (según lo expresado en la tabla 1), se convierte en el conocimiento posible de ser enseñado en un curso universitario donde se pretendan abordar aspectos metacientíficos de la biología.

Cabe aclarar, que estas problemáticas de la disciplina podrán presentarse en relación con los intereses de los estudiantes y con cuestionamientos actuales y contextuales, pero sobre este aspecto falta mayor exploración.

\section{Conclusiones}

El análisis epistemológico de la biología realizado sobre las posturas de Mayr (1998), Coleman (2002), Jacob (1970) y Piaget (1979), bajo los referentes teóricos ofrecidos por Toulmin (1977), proporcionó información sobre los cinco criterios epistemológicos: 1) Los problemas fundamentales de la biología. 2) Sus propósitos. 3) Los conceptos y teorías que resultan de dar respuestas a sus problemas. 4) Los procedimientos metodológicos seguidos. 5) Las posturas filosóficas predominantes en el pensamiento biológico.
Estos criterios que permiten a Toulmin delimitar una disciplina, proporcionan, en el contexto educativo, unos referentes de selección del conocimiento disciplinar requerido en la formación sobre ella.

Con esto se contribuye a: 1) La construcción de una postura epistemológica de la biología propia (entre otras). 2) Mostrar los aportes de la epistemología de una disciplina particular, en este caso la biología, para la toma de decisiones de orden curricular que debe realizar un maestro de ciencias, específicamente en lo que se refiere a la selección del conocimiento a enseñar. 3) Proponer conocimiento biológico y metacientífico para enseñarse en un curso universitario para la formación inicial de educadores en ciencias naturales.

Este conocimiento no solo corresponde a los contenidos conceptuales, sino también al conocimiento de las problemáticas que permitieron el desarrollo de la disciplina, las posturas epistemológicas desde donde se dieron esas problemáticas y conceptos, los propósitos que se plantearon en diferentes momentos y se encontraban asociados a las problemática y las metodologías desarrolladas para abordar las problemáticas y validar el conocimiento construido. Con estos conocimientos se podrá tener una idea más global de una disciplina.

Cabe tener en cuenta que la validez de la investigación de carácter teórico titulada "Elementos epistemológicos de la biología como referentes para su enseñanza" en la cual se basa este artículo, dependerá de su aplicación en propuestas de enseñanza de la biología, lo cual se espera llevar a cabo en otro momento de la investigación. 
Finalmente, a manera de recomendación, se sugiere para posibles investigaciones de este orden, abordar las formas de cómo se podría enseñar la biología reconociendo las diferencias epistemo- lógicas de sus diversas ramas; así por ejemplo, cómo podría ser el abordaje didáctico de la evolución, diferenciado del abordaje didáctico de la fisiología.

\section{Bibliografía}

Adúriz, A. (2005). Una introducción a la naturaleza de la ciencia. La epistemología en la enseñanza de las ciencias naturales. Buenos Aires: Fondo de cultura económica.

Bachelard, G. (1997). La formación del espíritu científico. México: Siglo XXI Editores.

Canguilhem, G. (1975). La concepción del concepto de reflejo en los siglos XVII y XVIII. Barcelona: Avance.

Coleman, W. (2002). La biología en el siglo XIX: problemas de forma, función y transformación. México: Fondo de cultura económica.

Colombo, L. y Salinas, J. (2004). ¿Es importante la epistemología de las ciencias en la formación de investigadores y de profesores en física? Enseñanza de las Ciencias, 22 (3), 455-462.

De Pro, A. (2003). La construcción del conocimiento científico y los contenidos de ciencias. En Jiménez, M., Caamaño, A., Pedrinaci, E. y De Pro, A. Enseñar Ciencias. Barcelona: Editorial Grao, 33-54.

Díaz Barriga, F. (1998, Octubre-Diciembre). Una aportación a la didáctica de la historia. La enseñanza- aprendizaje de habilidades cognitivas en el bachillerato. Perfiles educativos, No. 82. Universidad Autónoma de México.

Duit, R. (2006, Julio-Septiembre). La investigación sobre enseñanza de las ciencias. Un requisito imprescindible para mejorar la práctica educativa. Revista Mexicana de investigación educativa Vol. 11, No. 30, 741-770.

Duschl, R. (1997). Renovar la enseñanza de las ciencias. Importancia de las teorías y su desarrollo. Madrid: Narcea.

Escobedo, H. (1995, Enero-Febrero). Pensando en la formación de los docentes del tercer milenio. Revista actualidad educativa, Bogotá: 11-19.

Gil, D. (1991). ¿Qué hemos de saber y saber hacer los profesores de ciencias? (intento de síntesis de las aportaciones de la investigación didáctica). En Revista Enseñanza de las Ciencias, 9 (1), 69-77.

Gil, D. (1993). Contribuciones de la historia y de la filosofía de las ciencias al desarrollo de un modelo de enseñanza/aprendizaje como investigación. Enseñanza de las Ciencias, 11 (2), 197-212.

Giordan, A. et al (1988). Conceptos de Biología 1. España: Editorial Labor, S.A.

Gutiérrez, J. (2000). Fundamentos pedagógicos y didácticos. En Perales, F.J. y Cañal, P. (Eds.). Didáctica de las ciencias experimentales. Teoría y práctica de la enseñanza de las ciencias. Alcoy: Marfil. 2000, 109-137 
Hessen, J. (1998). Teoría del conocimiento. Colombia: Ediciones Universales.

Jacob, F. (1986). La lógica de lo viviente. Barcelona: Biblioteca científica Salvat.

Jimenez, M. (Abril, Mayo, Junio 1996). La variabilidad en la descendencia: comparación de teorías explicativas. Alambique No. 008, 33-41.

Jiménez, M. (2003). La enseñanza y el aprendizaje de la biología. En Jiménez, M., Caamaño, A., Pedrinaci, E., De Pro, A. (2003) Enseñar Ciencias. Barcelona: Editorial Grao.

Kuhn, T. (2004). La estructura de las revoluciones científicas. México: Fondo de Cultura Económica.

Lakatos, I. (1978). La metodología de los programas de investigación científica. Madrid: Alianza Editores.

Lecourt, D. (1973). La historia epistemológica de Georges Canguilhem. En: Para una crítica de la epistemología. Argentina: Siglo XXI Argentina editores, S. A., 65-95.

Maturana, H. y Varela, F. (1990). El árbol del conocimiento: las bases biológicas del conocimiento humano. España: Editorial Debate.

Mayr, E. (1998). Así es la biología. Madrid: Editorial Debate.

Mayr, E. (2006). Por qué es única la biología. Consideraciones sobre la autonomía de una disciplina científica. Buenos Aires: Katz Editores.

Mellado, V. y Carracedo, D. (1993). Contribuciones de la filosofía de la ciencia a la didáctica de las ciencias. Enseñanza de las Ciencias. 11 (3), 331-339.

Monod, J. (1993). El azar y la necesidad: ensayo sobre la filosofía natural de la biología moderna. Metatemas. Libros para pensar la ciencia.
Mosquera, C. (2005). El papel de la historia y la epistemología de la ciencia en la didáctica contemporánea de las ciencias. En: Tendencias del pensamiento educativo científico. Simposio Internacional sobre Enseñanza de las Ciencias. Cátedra Institucional Héctor Gómez Lora.

Pérez, C. (1992). ¿Qué puede ser la epistemología? Texto de ponencia de Jornada Académica en el Departamento de Psicología de la Universidad de Chile.

Pérez, C. (1998). Memorias seminario epistemología de la ciencia. Junio 3-7 de 1996. Universidad del Valle (Colombia).

Piaget, J. (1979). Introducción a la epistemología genética. El pensamiento biológico, psicológico y sociológico. Buenos Aires: PAIDÓS.

Rengifo, L. (2008). Elementos epistemológicos de la biología como referentes para su enseñanza. Trabajo de investigación de maestría en educación énfasis en enseñanza de las ciencias naturales. Cali: Universidad del Valle.

Sánchez, G. y Valcárcel, M. (2000). ¿Qué tienen en cuenta los profesores cuando seleccionan el contenido de enseñanza? Cambios y dificultades tras un programa de formación. Enseñanza de las Ciencias, 18 (3), 423-437.

Serres, M. (1991). Historia de las Ciencias. Ediciones Cátedra S.A.

Toulmin, S. (1977). La Comprensión Humana I. El uso colectivo y la evolución de los conceptos. Versión española de Néstor Míguez. Madrid: Alianza Editorial.

Valbuena, E. (2007). El conocimiento didáctico del contenido biológico: estudio de las concepciones disciplinares y didácticas de futuros docentes de la 
Universidad Pedagógica Nacional (Colombia). Tesis doctoral. Universidad Complutense de Madrid.

Zambrano, A. (2000). Relación entre el conocimiento del estudiante y el conocimiento del maestro en las ciencias experimentales. Universidad del Valle.

Zambrano, A. (2003). Cuestiones históricas y epistemológicas en torno a la enseñanza de las ciencias. En: Formación del pensamiento científico. Cátedra ICFES Agustín Nieto Caballero.
Zambrano, A. (2005). Documento El Programa de Tecnología en Acuicultura. Material inédito.

Zambrano, A. y Fundación Promigas. (2006). La enseñanza de las ciencias naturales y la educación ambiental en instituciones educativas oficiales del distrito de Barranquilla. Colombia.

Zambrano, A. (2008). Material sobre la Filosofía y Epistemología de la Ciencia. Manuscrito no publicado, preparado para el Doctorado Interinstitucional en Educación UPN-UD-UV. 